\title{
European clinical guidelines for Tourette Syndrome and other tic disorders. Part IV: Deep brain stimulation
}

Kirsten R. Müller-Vahl ${ }^{1}$, Danielle C. Cath ${ }^{2}$, Andrea E. Cavanna ${ }^{3}$, Sandra Dehning ${ }^{4}$, Mauro Porta $^{5}$, Mary M Robertson ${ }^{6}$, Veerle Visser-Vandewalle ${ }^{7}$ and the ESSTS Guidelines Group ${ }^{8}$

1 Clinic of Psychiatry, Socialpsychiatry and Psychotherapy, Hannover Medical School, Hannover, Germany, e-mail: mueller-vahl.kirsten@mh-hannover.de

2 Department of Clinical \& health psychology, Utrecht University/ Altrecht Academic Anxiety Outpatient services, Utrecht, the Netherlands

${ }^{3}$ Department of Neuropsychiatry, Birmingham and Solihull Mental Health NHS Foundation, Birmingham, UK

${ }^{4}$ Department of Psychiatry and Psychotherapy, Ludwig-Maximilian University Munich, Munich, Germany

${ }^{5}$ Movement Disorders and Tourette Centre, IRCCS Galeazzi, Milan, Italy

${ }^{6}$ Department of Mental Health Sciences, UCL, London, UK

${ }^{7}$ Department of Neurosurgery, University Hospital Maastricht, Maastricht, The Netherlands

${ }^{8}$ Members of the ESSTS Guidelines Group: Christos Androutsos, Harald Aschauer, Gillian Baird, Netty Bos-Veneman, Ariana Brambilla, Francesco Cardona, Virginie Czernecki, Alan Eapter, Luca Farkas, Julia Gadaros, Andreas Hartmann, Elizabeth Hauser, Isabel Heyman, Tammy Hedderly, Pieter Hoekstra, Anne Korsgaard, Georgina Jackson, Linnea Larsson, Andrea Ludolph, Davide Martino, Claudia Menghetti, Nanette Mol Debes, Norbert Muller, Alexander Munchau, Tara Murphy, Richard Musil, Peter Nagy, Judith Nurnberger, Ben Oostra, Perry Paschou, Massimo Pasquini, Kirsten Plessen, Hugh Rickards, Renata Rizzo, Veit Roessner, Aribert Rothenberger, Domenico Servello, Liselotte Skov, Jeremy Stern, Gerd Strand, Zsannett Tarnok, Cristiano Termine, Jolande Van der Griendt, Cara Verdellen, Ebba Wannag, Claudia Wenzel, Tomas Wolanczyck

\section{Corresponding author:}

Kirsten R Müller-Vahl, M.D.

Clinic of Psychiatry, Socialpsychiatry and Psychotherapy

Hannover Medical School

Carl-Neuberg-Str.1

30625 Hannover

Germany

Keywords: tics, Tourette, depp brain stimulation, treatment, guidelines 


\begin{abstract}
Objective: Ten years ago deep brain stimulation (DBS) has been introduced as an alternative and promising treatment option for patients suffering from severe Tourette Syndrome (TS). It seemed timely to develop a European guideline on DBS by a working group of the European Society for the Study of Tourette Syndrome (ESSTS).
\end{abstract}

Methods: For a narrative review a systematic literature search was conducted and expert opinions of the guidelines group contributed also to the suggestions.

Results: Of 63 patients reported so far in the literature 59 had a beneficial outcome following DBS with moderate to marked tic improvement. However, randomized controlled studies including a larger number of patients are still lacking. Although persistent serious adverse effects (AEs) have hardly been reported, surgery- (e.g., bleeding, infection) as well as stimulation-related AEs (e.g., sedation, anxiety, altered mood, changes in sexual function) may occur.

Conclusion: At present time, DBS in TS is still in its infancy. Due to both different legality and practical facilities in different European countries these guidelines, therefore, have to be understood as recommendations of experts. However, among the ESSTS working group on DBS in TS there is general agreement that, at present time, DBS should only be used in adult, treatment resistant, and severely affected patients. It is highly recommended to perform DBS in the context of controlled trials. 


\section{Introduction}

Tourette Syndrome (TS) is a chronic motor and vocal/phonic tic disorder. After the tic onset at the age of about $6-8$ years, tics have a waxing and waning course and reach a maximum at around 12 years. In the majority of patients tics decrease during adolescence or early adulthood. In adulthood most patients' tics are mild to moderate and medical treatment is less necessary than during childhood [7]. In those patients suffering from disabling tics behavioural therapy and/or drug treatment (see $[33,40])$ is recommended.

In a small number of patients tics are severe or even extreme and available treatment options are ineffective or cause intolerable adverse effects (AEs). In most of these severely affected patients, in addition, several comorbidities such as attention-deficit/hyperactivity disorder (ADHD), obsessive-compulsive disorder (OCD), depression, anxiety, and self-injurious behaviour (SIB) exist. Due to both tics and comorbidities quality of life is significantly impaired in most of these patients. When these patients are considered refractory to standard drug treatments in adequate doses and treatment periods, neurosurgery may have to be considered.

In TS, ablative surgery was performed for the first time in 1955 [38]. The first surgical treatment using the thalamus as a target was undertaken in 1970 by Hassler and Dieckmann [15] performing thalamotomy in the centromedial parafascicular complex (CM-Pf) in three patients resulting in a tic reduction of $70-100 \%$ [31]. Subsequently Babel et al. [4] reported about a tic reduction in 14 of 17 patients after ventriculography based stereotactic zona incerta (ZI) and ventrolateral/lamella medialis thalamotomy (VL/LM). However, in 69\% of these patients post-operative complications were described.

In 1999 for the first time (thalamic) deep brain stimulation (DBS) was suggested as an alternative therapeutic option for treatment resistant, severely affected patients with TS [39]. Since then, different targets have been used. While DBS is a well established treatment option 
in different neurological disorders including Parkinsons's disease, dystonia, and tremor, in TS DBS is still experimental.

Review of the literature (based on MEDLINE search of studies on DBS between 1970 and June 2010 and expert opinion of the ESSTS Guidelines Group)

So far, 24 studies including a total of 63 patients have been published describing the results of DBS in TS and chronic tic disorder. Most of these reports $(n=18)$ describe DBS in single patients (table 1). Only two reports included larger case series with 18 [34] and 32 patients (including the 18 patients reported earlier) [35], respectively. Three randomized studies including one (prospective double-blind (i.e. neither patient nor surgeon/investigator know if stimulation is 'on' or 'off') " $\mathrm{N}$ of 1" trial) [16], three (controlled double-blind randomized cross-over trail) [46], and five (prospective double-blind randomized) [21] patients, respectively, have been conducted so far (table 1). Taking all these data together, in 59 of 63 TS patients (93.7\%) DBS resulted in a significant tic improvement (table 2). In some cases, in addition, an amelioration of different comorbidities occurred (table 2). Although no serious persistent AEs have been reported so far, surgical- as well as stimulation-related AEs may occur (table 3). In a recent study long-term outcome (after 24 months) in 15 patients was evaluated describing sustained tic reduction and improvement of behavioural symptoms and no alterations in cognitive functions [28].

In TS patients the most often used targets of stimulation are the thalamus (CM-Pf) and the globus pallidus internus (GPi). In the literature, however, seven different targets have been described so far in patients with chronic tics: thalamus (CM-Pf and CM-Spv (substantia periventricularis)/nucleus ventralis oralis intermedius (Voi)), GPi (postero-ventrolateral and anteromedial part), nucleus accumbens (NA), anterior limb of the internal capsule (AIC), and subthalamicus nucleus (STN) (table 1). However, the specific coordinates used in different 
centres may differ slightly. In addition, the globus pallidus externus (GPe) has been suggested as a promising target ( $\mathrm{n}=7$ patients) (since preliminary results are published only in abstract form $[41,42]$, data are not included in this review). The rational to use different targets is that all targets belong to the ventral striatal-thalamo-cortical circuitries which are thought to be dysfunctional in TS. In the beginning, the same thalamic targets were targeted which were subject to stereotactic ablation by Hassler et al. in the 1960s [15]. Subsequently, other targets were selected that have been successfully used in other neurological disorders.

It can be assumed that - in addition to the patients reported in the literature $(n=63)$ - DBS has been performed in more TS patients without publication of the results. Since it can be speculated that beneficial results are more likely to be reported than unfavourable data, one should be cautious to prematurely conclude that DBS is indeed effective in almost all patients. 


\section{Recommendations}

It has to be emphasized that the following recommendations are based on current knowledge. This, therefore, acknowledges that further studies and knowledge might result in substantially different recommendations. Our recommendations are given against the background that up to now there are no randomized controlled studies available including a sufficiently large number of patients. Hence, it can not entirely be excluded that at least in some of the patients beneficial effects following DBS are related to placebo effects or to the waxing and waning course of the symptomatology. Therefore, the aim in the near future must be to join forces by conducting blinded controlled trials including a sufficient number of patients and/or to share databases to combine samples in order to obtain sufficiently large sample size. This is best established by collaborating among centres and sharing databases.

At present time, DBS in TS is still in its infancy. However, there is general agreement that even today DBS is a promising treatment option in severely affected, treatment resistant TS patients. It probably can not only reduce tics, but also comorbidities such as OCB/OCD, aggression, SIB, impulsivity, depression, and anxiety. Albeit the presence of severe tics is the primary inclusion criterion for DBS, it should be considered that quality of life is often more impaired by comorbidities than tics. Successful tic reduction following DBS, therefore, does not necessarily improve quality of life significantly [13].

Although it is the aim of this paper to give consistent European guidelines, it can not be ignored that both legal and practical circumstances differ across European countries and may influence both decision making and practical issues regarding DBS in TS. These guidelines, therefore, should be understood as a recommendation and are certainly not a stipulation. However, there is agreement that patients who wish DBS but do not fulfil below mentioned inclusion criteria should be excluded from DBS. 
Recommendations for both the selection of patients for DBS treatment including the assessment and study design are mainly driven by expert opinion since evidence from RCTs is scarce. Guidance has been given by other authors before [3, 6, 23-25, 27, 29, 43]. However, there is a vivid debate about some of these recommendations published so far [27, 30, 32, 44]. Based on the most considered guidelines published by Mink et al. [24], here the European Society for the Study of Tourette Syndrome (ESSTS) working group on DBS in TS wants to give revised clinical guidelines based on the current level of knowledge. First, we want to display those recommendations which are undisputable, followed by those that are up to debate.

\section{Undisputed recommendations}

Diagnosis of TS or a chronic tic disorder.

Diagnosis is approved by a clinician who is experienced in the diagnosis and treatment of tic disorders.

Tics are the main and not only secondary symptoms.

Tics are severe (for definition see below).

Tics cause significant impairment in quality of life in the domains of relationships, home environment and/or school/work.

Tics are treatment resistant (for definition see below).

Comorbidities such as ADHD, OCD, depression, anxiety disorder, and SIB have been adequately treated, i.e. according to respective guidelines.

The patient does not suffer from tics, OCB, or SIB that will lead to a damage of the electrodes or the stimulator.

No existence of a major depression and/or acute suicidal tendencies at time of operation. No other severe medical, neurological, psychiatric, or cognitive disorders that inordinately increase the risk of anaesthesia, operative procedure, and DBS. 
The patient is treatment compliant and lives in a stable psychosocial environment.

The patient or his/her legal representative has given written informed consent before DBS. In the latter case the patient should at least give assent.

If DBS is performed in the context of a study, the study design has been approved by a local ethic committee (or the IRB in USA).

DBS in TS should be undertaken only in centres where there are both acknowledged TS and DBS experts.

A close collaboration between surgeons and clinicians (either neurologists or psychiatrists or both) is guaranteed.

To all patients supportive psychotherapy should be recommended after surgery.

\section{Issues that are debatable and therefore no unequivocal recommendations can be given}

1. What should be the minimum age of a patient?

There is agreement among all experts that DBS should be performed only in adult patients. However, while some authors recommend a minimum age of 25 years, others suggest 18 years.

Rationale:

Some expert groups [24] recommend an age limit of $\geq 25$ years (with rare potential exceptions). However, during the last 10 years, 11 patients (18\%) younger than 25 years have already received DBS (table 1) and there is no evidence that DBS is less efficacious in these young patients, although direct comparisons are missing. However, since data on the course of tics and comorbidities in adolescents with TS are rare, at present time it remains unclear whether (and to what extent) severely affected patients at the age of 18 may await a significant improvement until the age of 25. 
2. How long should tics persist at minimum before DBS should be performed?

Tics should last at minimum 5 years before DBS should be performed (but not before the age of 18 and 25 , respectively).

Rationale:

Most likely, tics start at age 6-8 years. This means that at age 18, tics already persist for 10-12 years. Since fluctuations of tics are most obvious during the early course of the disease, DBS should not be performed at that time.

3. How long should tics be "severe" before DBS should be performed?

Tics should be severe for at least one year before DBS should be performed.

Rationale:

Tics wax and wane and often improve spontaneously within weeks or months. From the clinical experience it is not very likely that severe tics in adults will improve substantially when persisting for more than one year.

4. Which measurement(s) and which cut-off should be used to determine tics as "severe"?

The expert-rated Yale Global Tic Severity Scale (YGTSS) [19] with a cut-off at $\geq 35$ of maximal 50 points should be used for tic rating to determine tic severity as suggested before [24].

Rationale:

The YGTSS is the most often used tic rating scale. A score of $\geq 35$ of maximal 50 points requires on average for at least one tic form (motor or vocal) a mean tic score of 4 and for the other tic form of 3 (range, 0-5). This cut-off seems to be adequate to display tics as "severe" and psychosocially relevant. 
5. What should be done when a patient suffers from severe tics "by history" but tic rating yields "only" mild to moderate tics (YGTSS $<35$ of maximal 50 points)?

While some authors suggest to perform DBS in this (rare) situation, others do not recommend DBS in these situations.

Rationale:

Advocates would consider DBS, if reports by both the patient and reliable family members/friends describe undeniable severe tics, provided a home made videotape indeed documents severe tics (YGTSS score $\geq 35$ of maximal 50 points) at different circumstances. Tics often fluctuate, can be suppressed and are influenced by several environmental factors. In rare cases it is conceivable that even in severely affected patients tics observed during a medical examination may not represent real tic severity.

Opponents would suggest a cognitive behavioural treatment program_first because in these patients it is strongly suggested that tics are suppressible and this characteristic should be used in a behavioural therapy program such as habit reversal training or exposure to premonitory sensations with response prevention.

6. How shall treatment resistance be defined?

"Treatment resistance" in relation to the indication of DBS in TS should be assumed if treatment with three different drugs including both a typical and an atypical neuroleptic drug $(\mathrm{NL})$ in adequate dosage over an adequate period of time does not result in a significant tic reduction or leads to unacceptable AEs. If available, behavioural treatment (see [40]) should have been performed as well for at least 12 sessions without any substantial effect. Since haloperidol is the only drug that is formally licensed in many European countries for the indication tics and TS, some authors, therefore, suggest that failure of this drug already implicates treatment resistance.

Rationale: 
There is no generally accepted definition available for "treatment resistance" in TS. Although different patients may respond in a different way to different NL, three different NL seem to be adequate to determine treatment resistance. Since clonidine is less commonly used in Europe compared to the USA and many European experts are convinced that clonidine is less effective compared to NL, we believe that treatment with clonidine must not be undertaken to determine "treatment resistance". Although several other drugs have been recommended for the treatment of tics, none of these drugs is approved or can be recommended without reservation.

7. Which target should be selected?

At present time (based on clinical experience and theoretical knowledge) either thalamus (CM-Pf and/or CM-Pf/Voi) or GPi (postero-ventrolateral or anteriormedial) is recommended by most experts. However, some centres consider the NA (AIC) as first choice target as well. Rationale:

So far, eight different targets have been suggested as effective in TS. However, thalamic stimulation has been performed by far most frequently, followed by GPi stimulation. Although at present time, no recommendation can be given which target is the optimal one (because studies are lacking to answer this question), thalamus and GPi are the most reasonable targets. However, it is unclear whether the CM-Pf/Voi or CM-Pf and the GPi postero-ventrolateral ("sensori-motor component") or anteriormedial ("limbic component"), respectively, should be preferred. At this stage it is unclear whether different targets should be chosen depending on the respective clinical symptomatology. There is no obvious reason for failure of thalamic stimulation in two patients reported so far [21].

8. How many electrodes at how many targets should be stimulated simultaneously? In general, bilateral stimulation at one target should be performed. 
Rationale:

In the vast majority of patients, DBS has been performed bilaterally at one target. There is only weak evidence that simultaneous stimulation at two different targets (thalamus+GPi, AIC/NA+thalamus) bilaterally (= 4 electrodes) is superior to bilateral stimulation at one target $[16,35,46]$. However, there is some evidence that bilateral stimulation is superior to unilateral (GPi) stimulation [14]. In a small number of TS patients with severe comorbid OCD so called "rescue procedure" (AIC plus ventralis oralis/centromedianus-parafascicularis (VoCM-Pf) stimulation) has been suggested as promising [35].

9. Should DBS be performed only in the context of controlled studies?

If possible, DBS indeed should be performed in the context of controlled and double-blind (including “off"-stimulation) studies including larger and carefully characterized groups of patients. If reasonable, patients, therefore, should be referred to a suitable study centre. The aims of further studies are (1) to evaluate efficacy of DBS at all, (2) to compare efficacy of different targets, and (3) to ascertain whether specific clinical symptoms may predict a good or bad response to DBS. Therefore, not only tic severity but also comorbidities as well as cognitive performance should be assessed. Follow-up after DBS should be as long as possible (but at least 24 months) to evaluate not only short but also long-term out-come. In the context of controlled trials implantation of four electrodes at two different targets is recommended to provide the opportunity to compare directly the efficacy of different targets in one single patient.

\section{Conclusions}

DBS is a very promising treatment option in adult, treatment resistant, severely affected TS patients. Randomized double-blind controlled studies including a larger number of patients are necessary to corroborate available results obtained from case reports and small clinical 
trials. If DBS indeed proves successful new guidelines have to be formulated. Subsequent recommendations should take into account the discussion about several aspects regarding patients' selection, operative procedure, follow-up, and study design. 


\section{Conflict of interest}

Commercial firms and governmental organisations did not play a role in, or fund, the development of these guidelines. Kirsten R. Müller-Vahl, Danielle C. Cath, Andrea E. Cavanna, Sandra Dehning, Veerle Visser-Vandewalle declare that they have no conflict of interest.

Potential conflicts of interest: Mauro Porta: scientific advisory board of Lundbeck, the Netherlands; Mary Robertson has recently received a grant from the Tourette's Action-UK (Grant to support Dr AE Cavanna), she has also received honoraria from Janssen-Cilag, Eli Lilly, and has received Royalties for books from Blackwells Science, David Fulton/Granada/Taylor Francis, Oxford University Press and also Jessica Kingsley Publishers, she also sits on the Medical Advisory Board for the Italian Tourette Syndrome Association and The Tourette Syndrome Foundation of Canada; Davide Martino: honoraria for symposia from UCB Pharma, Chiesi Pharmaceuticals, Novartis, and Boehringer-Ingelheim.

\section{References}

1. Ackermans L, Temel Y, Bauer NJC, Visser-Vandewalle V (2007) Vertical gaze palsy after thalamic stimulation for Tourette syndrome: case report. Neurosurgery 61:E1100; discussion E1100.

2. Ackermans L, Temel Y, Cath D, van der Linden C, Bruggeman R, Kleijer M, Nederveen P, Schruers K, Colle H, Tijssen MA, Visser-Vandewalle V; Dutch Flemish Tourette Surgery Study Group (2006) Deep brain stimulation in Tourette's syndrome: two targets? Mov Disord 21:709-713

3. Ackermans L, Temel Y, Visser-Vandewalle V (2008) Deep brain stimulation in Tourette's Syndrome. Neurotherapeutics 5:339-344

4. Babel TB, Warnke PC, Ostertag CB (2001) Immediate and long term outcome after 
infrathalamic and thalamic lesioning for intractable Tourette's syndrome. J Neurol Neurosurg Psychiatr 70:666-671

5. Bajwa RJ, de Lotbinière AJ, King RA, Jabbari B, Quatrano S, Kunze K, Scahill L, Leckman JF (2007) Deep brain stimulation in Tourette's syndrome. Mov Disord 22:1346-1350

6. Black KJ (2009) Patient page. Deep brain stimulation for Tourette syndrome. Neurology 73:e87-90

7. Burd L, Kerbeshian PJ, Barth A, Klug MG, Avery PK, Benz B (2001) Long-term follow-up of an epidemiologically defined cohort of patients with Tourette syndrome. J Child Neurol 16:431-437

8. Burdick A, Foote KD, Goodman W, Ward HE, Ricciuti N, Murphy T, Haq I, Okun MS (2010) Lack of benefit of accumbens/capsular deep brain stimulation in a patient with both tics and obsessive-compulsive disorder. Neurocase 16:321-30

9. Dehning S, Mehrkens J, Müller N, Bötzel K (2008) Therapy-refractory Tourette syndrome: beneficial outcome with globus pallidus internus deep brain stimulation. Mov Disord 23:1300-1302

10. Diederich NJ, Kalteis K, Stamenkovic M, Pieri V, Alesch F (2005) Efficient internal pallidal stimulation in Gilles de la Tourette syndrome: a case report. Mov Disord 20:1496-1499

11. Dueck A, Wolters A, Wunsch K, Bohne-Suraj S, Mueller J, Haessler F, Benecke R, Buchmann J (2009) Deep brain stimulation of globus pallidus internus in a 16-yearold boy with severe tourette syndrome and mental retardation. Neuropediatrics 40:239-242

12. Flaherty AW, Williams ZM, Amirnovin R, Kasper E, Rauch SL, Cosgrove GR, Eskandar EN (2005) Deep brain stimulation of the anterior internal capsule for the treatment of Tourette syndrome: technical case report. Neurosurgery 57(4 
suppl):E403; discussion E403

13. Foltynie T, Martinez-Torres I, Zrinzo L, Joyce E, Cavanna A, Jahanshahi M, Limousin P, Hariz M (2009) Improvement in vocal \& motor tics following DBS of motor GPi for Tourette syndrome, not accompanied by subjective improvement in quality of life - A case report. Mov Disord 24(suppl 1):S497-S498

14. Gallagher CL, Garell PC, Montgomery EB (2006) Hemi tics and deep brain stimulation. Neurology 66:E12

15. Hassler R, Dieckmann G (1970) [Stereotaxic treatment of tics and inarticulate cries or coprolalia considered as motor obsessional phenomena in Gilles de la Tourette's disease]. Rev Neurol (Paris) 123:89-100

16. Houeto JL, Karachi C, Mallet L, Pillon B, Yelnik J, Mesnage V, Welter ML, Navarro S, Pelissolo A, Damier P, Pidoux B, Dormont D, Cornu P, Agid Y (2005) Tourette's syndrome and deep brain stimulation. J Neurol Neurosurg Psychiatr 76:992-995

17. Houeto J, Giré P (2008) [Tics and Tourette syndrome: diagnosis, course and treatment principles]. Presse Med 37(2 Pt 2):263-270

18. Kuhn J, Lenartz D, Mai JK, Huff W, Lee S, Koulousakis A, Klosterkoetter J, Sturm V (2007) Deep brain stimulation of the nucleus accumbens and the internal capsule in therapeutically refractory Tourette-syndrome. J Neurol 254:963-965

19. Leckman JF, Riddle MA, Hardin MT, Ort SI, Swartz KL, Stevenson J, Cohen DJ (1989) The Yale Global Tic Severity Scale: initial testing of a clinician-rated scale of tic severity. J Am Acad Child Adolesc Psychiatry 28:566-573

20. van der Linden C, Colle H, Vandewalle V, Alessi G, Rijckaert D, de Waele L (2002) Successful treatment of tics with bilateral internal pallidum (GPi) stimulation in a 27year-old male patient with Gilles de la Tourette's syndrome (GTS). Mov Disord 17:P1130

21. Maciunas RJ, Maddux BN, Riley DE, Whitney CM, Schoenberg MR, Ogrocki PJ, 
Albert JM, Gould DJ (2007) Prospective randomized double-blind trial of bilateral thalamic deep brain stimulation in adults with Tourette syndrome. J Neurosurg 107:1004-1014

22. Martinez-Torres I, Hariz MI, Zrinzo L, Foltynie T, Limousin P (2009) Improvement of tics after subthalamic nucleus deep brain stimulation. Neurology 72:1787-1789

23. Mink JW (2009) Clinical review of DBS for tourette syndrome. Front Biosci (Elite Ed) 1:72-76

24. Mink JW, Walkup J, Frey KA, Como P, Cath D, Delong MR, Erenberg G, Jankovic J, Juncos J, Leckman JF, Swerdlow N, Visser-Vandewalle V, Vitek JL; Tourette Syndrome Association, Inc. (2006) Patient selection and assessment recommendations for deep brain stimulation in Tourette syndrome. Mov Disord 21:1831-1838

25. Neimat JS, Patil PG, Lozano AM (2006) Novel surgical therapies for Tourette syndrome. J Child Neurol 21:715-718

26. Neuner I, Podoll K, Lenartz D, Sturm V, Schneider F (2009) Deep brain stimulation in the nucleus accumbens for intractable Tourette's syndrome: follow-up report of 36 months. Biol Psychiatry 65:e5-6

27. Okun MS, Fernandez HH, Foote KD, Murphy TK, Goodman WK (2008) Avoiding deep brain stimulation failures in Tourette syndrome. J Neurol Neurosurg Psychiatr 79:111-112

28. Porta M, Brambilla A, Cavanna AE, Servello D, Sassi M, Rickards H, Robertson MM (2009) Thalamic deep brain stimulation for treatment-refractory Tourette syndrome: two-year outcome. Neurology 73:1375-1380

29. Porta M, Servello D, Sevello D, Sassi M, Brambilla A, Defendi S, Priori A, Robertson M (2009) Issues related to deep brain stimulation for treatment-refractory Tourette's syndrome. Eur Neurol 62:264-273

30. Poysky J, Jimenez-Shahed J (2007) Patient selection and assessment recommendations 
for deep brain stimulation in Tourette syndrome. Mov Disord 22:1366-1367; author reply $1367-1368$

31. Rickards H, Wood C, Cavanna AE (2008) Hassler and Dieckmann's seminal paper on stereotactic thalamotomy for Gilles de la Tourette syndrome: translation and critical reappraisal. Mov Disord 23:1966-1972

32. Riley DE, Whitney CM, Maddux BN, Schoenberg MS, Maciunas RJ (2007) Patient selection and assessment recommendations for deep brain stimulation in Tourette syndrome. Mov Disord 22:1366; author reply 1367-1368

33. Roessner V, Plessen K, Rizzo R, Skov L, Strand G, Stern J, Termine C, Hoekstra P, the ESSTS Guidelines Group. European clinical guidelines for Tourette Syndrome and other chronic tic disorders Part II: Pharmacological treatment. Eur Child Adolesc Psychiatry:

34. Servello D, Porta M, Sassi M, Brambilla A, Robertson MM (2008) Deep brain stimulation in 18 patients with severe Gilles de la Tourette syndrome refractory to treatment: the surgery and stimulation. J Neurol Neurosurg Psychiatr 79:136-142

35. Servello D, Sassi M, Brambilla A, Porta M, Haq I, Foote KD, Okun MS (2009) De novo and rescue DBS leads for refractory Tourette syndrome patients with severe comorbid OCD: a multiple case report. J Neurol 256:1533-1539

36. Shahed J, Poysky J, Kenney C, Simpson R, Jankovic J (2007) GPi deep brain stimulation for Tourette syndrome improves tics and psychiatric comorbidities. Neurology 68:159-160

37. Shields DC, Cheng ML, Flaherty AW, Gale JT, Eskandar EN (2008) Microelectrodeguided deep brain stimulation for Tourette syndrome: within-subject comparison of different stimulation sites. Stereotact Funct Neurosurg 86:87-91

38. Temel Y, Visser-Vandewalle V (2004) Surgery in Tourette syndrome. Mov Disord $19: 3-14$ 
39. Vandewalle V, van der Linden C, Groenewegen HJ, Caemaert J (1999) Stereotactic treatment of Gilles de la Tourette syndrome by high frequency stimulation of thalamus. Lancet 353(9154):724

40. Verdellen C, van de Griendt J, Hartmann A, Murphy T, the ESSTS Guidelines Group. European clinical guidelines for Tourette Syndrome and other tic disorders. Part III: Behavioural and psychosocial interventions. Eur Child Adolesc Psychiatry:

41. Vilela Filho O, Ragazzo P, Silva D, Souza J, Oliveira P, Ribeiro T (2008) Bilateral GPe-DBS for Tourette's Syndrome (Abstr.). Neurotarget 3:65

42. Vilela Filho O, Ragazzo P, Souza J, Silva D, Oliveira P, Piedimonte F, Ribeiro T (2010) Bilateral GPe-DBS for Tourette syndrome: A double-blind prospective controlled study of seven patients (Abstr.) In: Abstract Book of the ASSFN (American Society for Stereotactic and Functional Neurosurgery), 2010 Biennial Meeting: Bridging the Future of Neurosurgery, New York

43. Visser-Vandewalle V (2007) DBS in tourette syndrome: rationale, current status and future prospects. Acta Neurochir Suppl 97(Pt 2):215-222

44. Visser-Vandewalle V, Ackermans L, van der Linden C, Temel Y, Tijssen MA, Schruers KR, Nederveen P, Kleijer M, Boon P, Weber W, Cath D (2006) Deep brain stimulation in Gilles de la Tourette's syndrome. Neurosurgery 58:E590

45. Visser-Vandewalle V, Temel Y, Boon P, Vreeling F, Colle H, Hoogland G, Groenewegen HJ, van der Linden C (2003) Chronic bilateral thalamic stimulation: a new therapeutic approach in intractable Tourette syndrome. Report of three cases. $\mathbf{J}$ Neurosurg 99:1094-1100

46. Welter M, Mallet L, Houeto J, Karachi C, Czernecki V, Cornu P, Navarro S, Pidoux B, Dormont D, Bardinet E, Yelnik J, Damier P, Agid Y (2008) Internal pallidal and thalamic stimulation in patients with Tourette syndrome. Arch Neurol 65:952-957

47. Zabek M, Sobstyl M, Koziara H, Dzierzecki S (2008) Deep brain stimulation of the 
right nucleus accumbens in a patient with Tourette syndrome. Case report. Neurol Neurochir Pol 42:554-55 
Table 1 Main characteristics of studies published and patients (multiple mention possible).

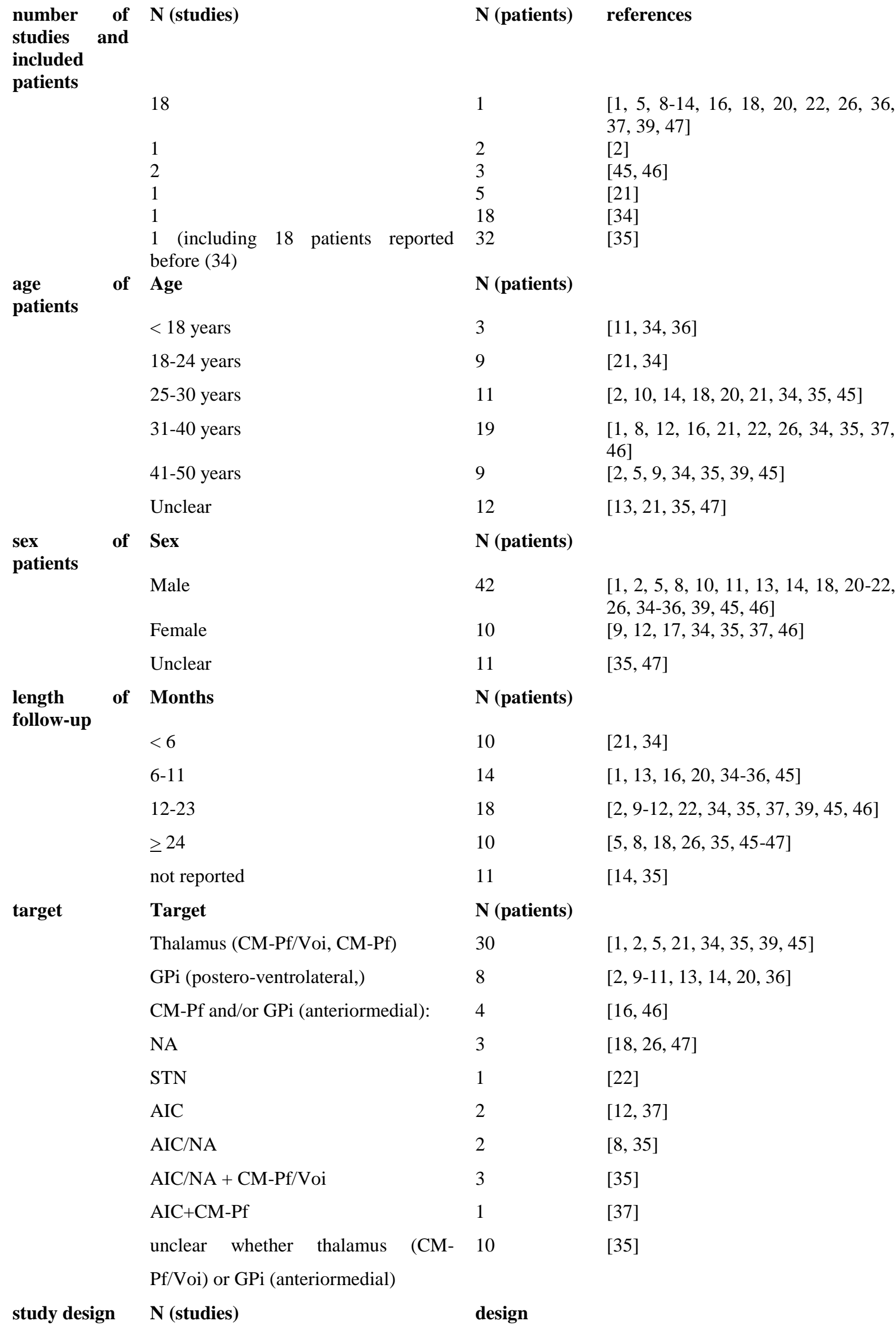

$[1,2,5,8,10,11,13,14,18,20-22$ $26,34-36,39,45,46]$ 
open, $\quad[1,2,5,8-14,18,20,22,26,34-37$, uncontrolled $39,45,47]$

(case

reports/series)

randomized,

$(16,21,46]$

double-blind 
Table 2 Improvement of tics and comorbidities according to the target (multiple mention possible).

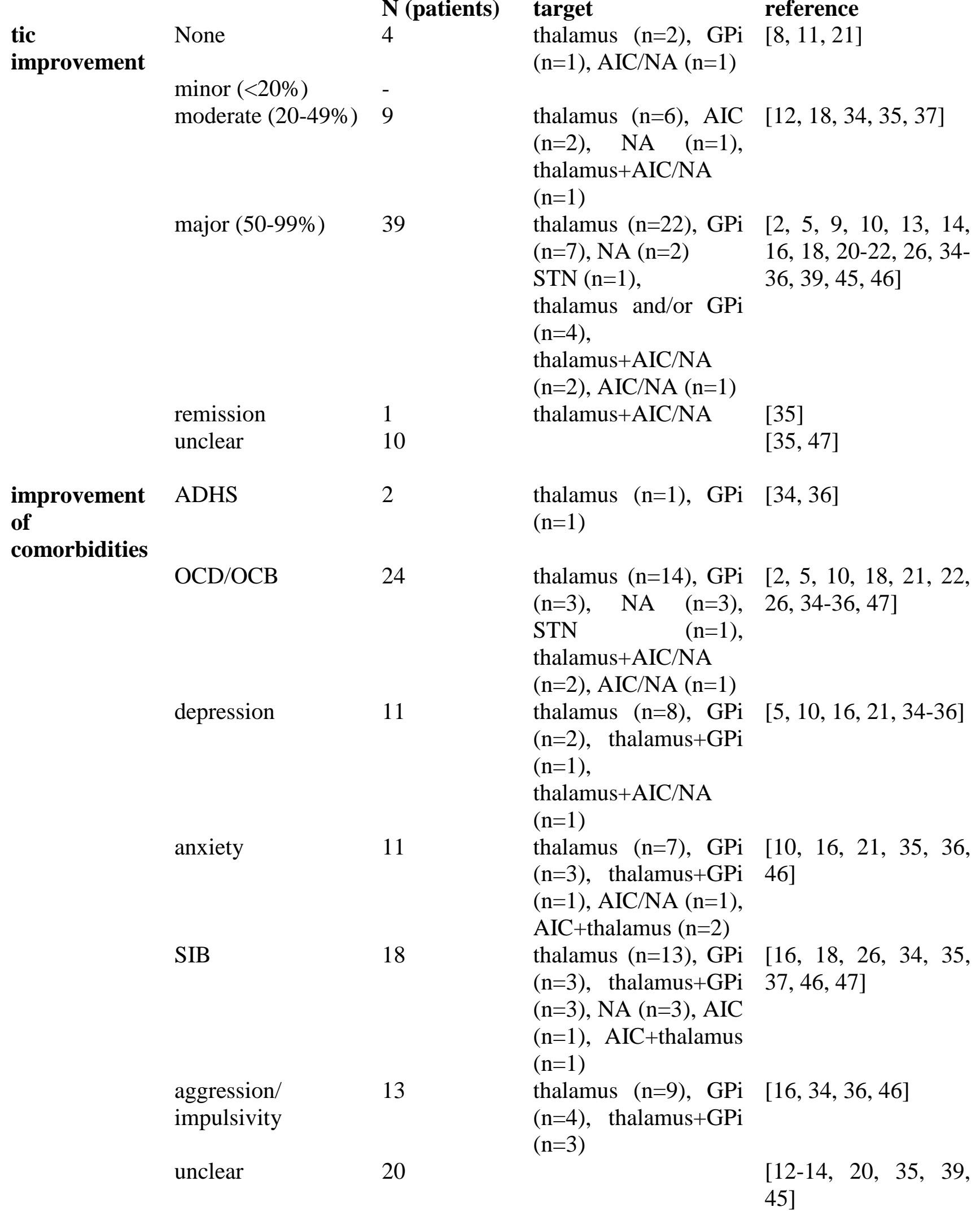


Table 3: Adverse effects (AEs) published so far (multiple mention possible)

\begin{tabular}{|c|c|c|c|c|}
\hline $\begin{array}{l}\text { kind of } \\
\text { AE }\end{array}$ & $\mathbf{A E}$ & $\begin{array}{l}\mathrm{N} \\
\text { (patients) }\end{array}$ & target & reference \\
\hline \multirow[t]{6}{*}{$\begin{array}{l}\text { surgery- } \\
\text { related } \\
\text { AE }\end{array}$} & $\begin{array}{l}\text { transient vertical gaze palsy due to a } \\
\text { small bleeding caudal to the tip of the } \\
\text { electrode }\end{array}$ & 1 & thalamus & {$[1]$} \\
\hline & abdominal haematoma & 1 & thalamus & [34] \\
\hline & wound healing problems & 1 & thalamus & {$[34]$} \\
\hline & traction pain & 2 & thalamus & {$[45]$} \\
\hline & $\begin{array}{l}\text { hematoma around the tip of the } \\
\text { electrode leading to unilateral } \\
\text { bradydyskinesea }\end{array}$ & 1 & GPi & {$[10]$} \\
\hline & $\begin{array}{l}\text { infection leading to left stimulator } \\
\text { removal }\end{array}$ & 1 & GPi & {$[14]$} \\
\hline \multirow[t]{14}{*}{$\begin{array}{l}\text { DBS- } \\
\text { related } \\
\text { AE }\end{array}$} & $\begin{array}{l}\text { sedation, fatique, reduced energy, } \\
\text { apathy, lethargy }\end{array}$ & 9 & $\begin{array}{l}\text { thalamus }(n=4) \text {, } \\
\text { GPi }(n=3), \text { AIC } \\
(n=2)\end{array}$ & $\begin{array}{l}{[2,10,12,} \\
13,37,45]\end{array}$ \\
\hline & weight loss & 1 & $\begin{array}{l}\text { thalamus }(n=1) \text {, } \\
\text { GPi }(n=1)\end{array}$ & {$[16]$} \\
\hline & $\begin{array}{l}\text { decrease in sexual functions, libido, } \\
\text { potency, ejaculation }\end{array}$ & 3 & thalamus $(n=3)$ & {$[2,45,46]$} \\
\hline & increased sexual drive & 1 & thalamus & {$[45]$} \\
\hline & transient blurring of vision & 4 & thalamus $(n=4)$ & [34] \\
\hline & upward ocular deviation & 1 & thalamus & [34] \\
\hline & Psychosis & 1 & $\begin{array}{l}\text { thalamus } \\
\text { unilateral } \mathrm{R}\end{array}$ & {$[21]$} \\
\hline & Nausea & 2 & GPi (n=2) & [46] \\
\hline & Vertigo & 2 & GPi $(n=2)$ & [46] \\
\hline & Anxiety & 2 & GPi $(n=2)$ & {$[13,46]$} \\
\hline & $\begin{array}{l}\text { short dystonic jerk when stimulators } \\
\text { were switched "on" }\end{array}$ & 1 & GPi & [2] \\
\hline & social avoidance & 1 & GPi & {$[36]$} \\
\hline & Depression & 2 & $\operatorname{AIC}(n=2)$ & {$[12,37]$} \\
\hline & (agitated) hypomania & 2 & $\operatorname{AIC}(n=2)$ & {$[12,37]$} \\
\hline \multirow{8}{*}{$\begin{array}{l}\text { no } \\
\text { AE/not } \\
\text { reported }\end{array}$} & & 19 & thalamus & {$\left[\begin{array}{lll}5, & 16, & 21,\end{array}\right.$} \\
\hline & & 3 & GPi & {$[9,16,20]$} \\
\hline & & 3 & NA & $\begin{array}{l}{[18, \quad 26,} \\
47]\end{array}$ \\
\hline & & 1 & STN & [22] \\
\hline & & 1 & thalamus+GPi & [16] \\
\hline & & 1 & AIC/NA & {$[35]$} \\
\hline & & 3 & $\begin{array}{l}\text { AIC/NA+CM- } \\
\text { Pf/Voi }\end{array}$ & {$[35]$} \\
\hline & & 10 & target unclear & {$[35]$} \\
\hline
\end{tabular}

